\title{
Synthesis of robust flexible polyethersulfone ultrafiltration membranes supported on non-woven fabrics for separation of NOM from water
}

\author{
Tumelo G Tshabalala', Edward N Nxumalo', Bhekie B Mamba' and Sabelo D Mhlanga1* \\ 'Nanotechnology and Water Sustainability Research Unit, College of Science, Engineering and Technology, University of South Africa, Florida, 1709, \\ Johannesburg, South Africa
}

\begin{abstract}
This work describes the synthesis of structurally robust ultrafiltration (UF) polyethersulfone (PES) membranes supported on three different types of non-woven fabrics (NWFs) prepared using a simple phase inversion method. The NWF supported membranes exhibited high mechanical strength compared to the unsupported PES membranes modified with polyvinyl pyrrolidone (PVP) due to the strength provided by the NWFs. The tensile strength of the supported PVP modified membranes was $\sim 7 \mathrm{MPa}$ compared to $\sim 2 \mathrm{MPa}$ observed for the PVP modified unsupported UF membranes. The use of the NWFs clearly provides robustness to the modified membranes. The membrane surfaces became hydrophilic with addition of PVP and the pore sizes increased with an increase in PVP concentration (scanning electron microscopy (SEM) results). The rejection of humic acid (as a model NOM compound) was $98 \%$ for PES on NWF1, while PES membranes supported on NWF2 and NWF3 gave rejections of $94 \%$ and $96 \%$, respectively; all with good fouling resistance. This work demonstrates that the use of a NWF support allows for the modification of the surface of the membranes without compromising the overall strength of the membranes, but more importantly the ability of the membranes to reject HA while exhibiting high resistance to fouling.
\end{abstract}

Keywords: polyethersulfone membrane, non-woven fabric, mechanical strength, fouling, polyvinyl pyrrolidone

\section{INTRODUCTION}

Natural organic matter (NOM) is known to exist in surface and ground waters and is the main component of organic carbon in aquatic systems (Särkkä et al., 2015). In order to remove NOM from water in a water treatment plant, its composition in the source water must be taken into consideration, since it may not be homogenous and also because the specific local environment determines the composition (Nkambule et al., 2012).

A well-known group of NOMs that exist in water sources and that affect water quality is humic substances (HS), which include: (i) humin, which is completely insoluble in water, (ii) humic acid (HA) which is insoluble at low $\mathrm{pH}$ and (iii) fulvic acid (FA) whose solubility is possible at any $\mathrm{pH}$. HA is said to form as a result of the culmination of condensation polymerisation reactions, amino acid sugar interactions, lignin biodegradation, and animal and plant decay (Ortiz-Martínez et al., 2016). The dangers of HA in water manifest as a result of the use of disinfection processes such as chlorination. HA combines with disinfectants to form disinfection by-products (DBPs), such as trihalomethanes, halonitromethanes, haloacetonitriles, haloamides, halofuranones, iodo-acids and others, which are known to be carcinogenic and have the potential of causing adverse effects to human life (Fan et al., 2014; Hu et al., 2016; Jian et al., 2016; Kim et al., 2015; Linge et al., 2013; Xue et al., 2014).

The effective removal of NOM is of critical importance in adhering to the set of DBP regulations in the continuous provision of safe drinking water. Ultrafiltration (UF) membranes permit the removal of colloidal particles, microorganisms and a

\footnotetext{
* To whom all correspondence should be addressed.

- +2711471 2104; e-mail:mhlansd@unisa.ac.za

Received 31 July 2015; accepted in revised form 6 September 2016
}

considerable amount of dissolved organic matter. These membranes have been very widely utilised in drinking water treatment as an alternative technology to conventional methods of purifying water (Schäfer, 2001; Domany et al., 2002; Chang et al., 2015; Zhang et al., 2015). NOM, e.g., humic acid, poses serious hindrance to membrane flux (flow of water across a membrane) by adsorbing on the membrane surfaces in a process known as fouling, wherein the pores of the membranes become blocked with time, resulting in a lower flux of water across the membrane (Elimelech et al., 2011; Vankelecom et al., 2003; Särkkä et al., 2015; Yunos et al., 2014). Fouling is a major challenge in the use of membranes for water purification; it increases operational costs and consequently results in diminished productivity of the water purification process (Kim and Dempsey, 2013). Thus, the fabrication of membranes with anti-fouling properties as well as having the capacity to reject the largest amounts of pollutants has become a matter of high priority in membrane technology. Alternatively, a membrane with high mechanical stability that can withstand high pressure is desirable.

Examples of typical UF membranes that have been used in the removal of NOM are listed in Table 1 (list is not exhaustive). The percentage rejections of NOM by these membranes are between 76 and $80 \%$. The flux values obtained were dependant on the functionalities introduced to the membrane. Recently, the incorporation of multi-walled carbon nanotubes (MWCNTs) was reported to increase the rejection of NOM by polyaniline/polyethersulfone (PANI/PES) blend membranes (Lee et al., 2016).

In this study, non-woven fabrics (NWFs) of three different types were used as supports for modified polyethersulfone (PES) membranes (Table 2). The use of these NWFs to support PES membranes is known to enhance the membrane's mechanical strength, improve performance and result in diminished fouling 
propensity (Violleau et al., 2005; Hou et al., 2012, Hegde et al., 2013). This study was focused on the use of a different class of NWFs in order to address issues such as flux, fouling and NOM rejection, while maintaining the desired structural integrity and antifouling properties of the modified PES membranes. The PES membranes supported on the NWFs were synthesized using the phase inversion method and their porosity was modified using polyvinyl pyrrolidone (PVP). We demonstrate the advantages of using the support materials with modified PES membranes and compare them to unsupported PES membranes in the removal of HA from water. The fouling resistance of the modified membranes is also demonstrated.

\section{MATERIALS AND METHODS}

\section{Materials}

PES resin, PVP with molecular weight of $29 \mathrm{KDa}$, dimethyl acetamide (DMAC) solvent and HA were purchased from Sigma Aldrich, South Africa. The non-woven fabrics, i.e., NWF1, NWF2 and NWF3 were purchased from Ahlstrom Co and Hirose Co in the USA. All materials were used as received without further purification. Table 2 shows the physicochemical properties of the NWFs used in this study. The SEM images provide a visual view of the surface structure of the NWFs. NWF2 had the highest permeability followed by NWF1 and then NWF3. NWF1 and NWF3 were made out of the same material but differed in thickness, as can be seen in the SEM images. We chose these fabrics in order to study the effect of the support thickness and porosity on the modified PES membranes.

\section{Membrane preparation}

The membranes were prepared via a phase inversion method (Hegde et al., 2013). PES pellets (20 wt \%) were dissolved in DMAC with stirring over a period of $24 \mathrm{~h}$ to form a PES viscous homogenous solution. PVP $(29 \mathrm{KDa})$ was added to the solution. The PVP additive was varied between $5 \mathrm{wt} \%, 10 \mathrm{wt} \%$ and $15 \mathrm{wt} \%$. The resulting solution was allowed to stand for $24 \mathrm{~h}$ in order to allow the gas bubbles generated during the reaction to settle. The prepared solutions were then cast on the three different NWFs (Fig. 1) with physicochemical properties described in Table 2. The NWFs were first attached onto a clean and dry glass plate using an adhesive tape. Using a casting knife with a blade height set at $200 \mu \mathrm{m}$, the polymer solution was cast on the NWFs attached to a glass plate and the glass was immediately immersed in de-ionized water to coagulate for a period of $15 \mathrm{~min}$ after which the membranes were rinsed in deionised water 3 times, for 30 min each (Fig. 1). Part of the membrane was then air-dried using filter paper and characterized.

\section{Membrane characterization}

Fourier transform-infrared (FT-IR) spectra of the membranes were collected from a Perkin Elmer 100 Spectrometer and were recorded with characteristic peaks in wave numbers from 650 to $4000 \mathrm{~cm}^{-1}$. Water contact angles were measured using a sessile drop method with a Data Physics optical goniometer, which is a contact angle measuring instrument with the droplet size controlled using a Gilmont syringe. Deionised water was used for contact angle analysis. Droplets from the syringe were directed to come into contact with the membrane at several different points on each membrane sample to obtain a series of contact angle pairs. All measurements were executed at room temperature.

\begin{tabular}{|c|c|c|c|}
\hline \multicolumn{4}{|c|}{$\begin{array}{c}\text { TABLE } 1 \\
\text { A list of selected UF membranes used to reject NOM in water }\end{array}$} \\
\hline UF membrane & $\begin{array}{l}\text { Highest flux } \\
\left(\mathrm{L} \cdot \mathrm{m}^{-2} \mathbf{h}^{-1}\right)\end{array}$ & $\begin{array}{l}\text { Rejection } \\
\text { (\%) }\end{array}$ & Reference \\
\hline $\begin{array}{l}\text { Polyphenyl- } \\
\text { sulfone/ } \\
\text { Polyetherimide }\end{array}$ & 225 & 79 & (Hwang et al., 2011) \\
\hline $\begin{array}{l}\text { PANI/PES/ } \\
\text { MWCNTs }\end{array}$ & 162 & 80 & (Lee et al., 2016) \\
\hline $\begin{array}{l}\text { Functionalised } \\
\text { PES }\end{array}$ & 113 & 76 & (Peeva et al., 2011) \\
\hline
\end{tabular}

Thermogravimetric analysis (TGA) was performed on a Perkin Elmer instrument with a heating rate of $10^{\circ} \mathrm{C} \cdot \mathrm{min}^{-1}$ over a temperature range of $30-900^{\circ} \mathrm{C}$ in air. TGA revealed essential information about the thermal stability of the membranes.

The surface and cross-sectional analyses of the membranes were executed using a JEOL-JSM-7500F scanning electron microscope (SEM) with an energy source of $200 \mathrm{kV}$. Images were formulated by directing a high beam of electrons through a sample and subsequently detected to create an image. The samples were first cryogenically fractured in liquid nitrogen. They were then securely mounted on aluminium stubs and coated with gold, in order to induce their capacity to conduct. Membranes were ultimately studied in order to understand the morphology of the bare membranes relative to the modified ones. To study the surface roughness of the fabricated membranes, a Veeco atomic force microscope with nanoscope v5.30r3sr3 utility software was used for this characterisation.

Tensile tests to determine the membrane tensile strength were carried out using an Instron 5966 Tester (Instron Engineering Corporation, USA) with a load cell of $10 \mathrm{kN}$. This was carried out under the tension mode at a single strain rate of $5 \mathrm{~mm} \cdot \mathrm{min}^{-1}$ at room temperature. The thin films measured approximately $25 \mathrm{~cm}$ by $10 \mathrm{~cm}$ by $(0.06-0.09) \mathrm{cm}$.

\section{Membrane testing and application}

A cross-flow system was used to test the membrane flux and rejection properties. The cross-flow system was first washed with soapy tap water through a circulation process to remove all the dirt which was present. The system was then rinsed thoroughly with deionised water. The synthesised PES NWF supported membranes were then assembled in the cells of the cross-flow system. Membranes were then compacted at a membrane pressure of $137.9 \mathrm{kPa}$ using deionised water for $4 \mathrm{~h}$. The water flux was then determined for all the membranes in the cross-flow system (see Fig. 2).

In a typical experiment, $5 \mathrm{~L}$ of $20 \mathrm{mg} \cdot \mathrm{L}^{-1} \mathrm{HA}$ solution was prepared to be used in rejection studies. The $\mathrm{pH}$ of the solution was set between 8 and 9 using $\mathrm{NaOH}$ to ensure complete dissolution, since HA is insoluble at lower $\mathrm{pH}$ values. This concentration of HA is approximately equivalent to NOM levels found in natural waters. The flux of the membranes were then determined at $137.9 \mathrm{kPa}$ by noting the time taken to collect $20 \mathrm{~mL}$ of the permeate volume, which was varied over $30 \mathrm{~min}$ intervals. The lower pressure was used to save energy. A typical seawater reverse osmosis plant uses pressure in the region of 6000 to $8000 \mathrm{KPa}$ (Water Reuse Association, 2011). The concentration of HA in the feed and collected permeate for each of the membranes was determined quantitatively using a Shimadzu UV-VIS spectrophotometer instrument, performed at a wavelength of $254 \mathrm{~nm}$ for absorbance measurements. The absorbances were related to the HA concentration; these concentrations were then used to calculate percentage rejections $(\% \mathrm{R})$ for each membrane. 


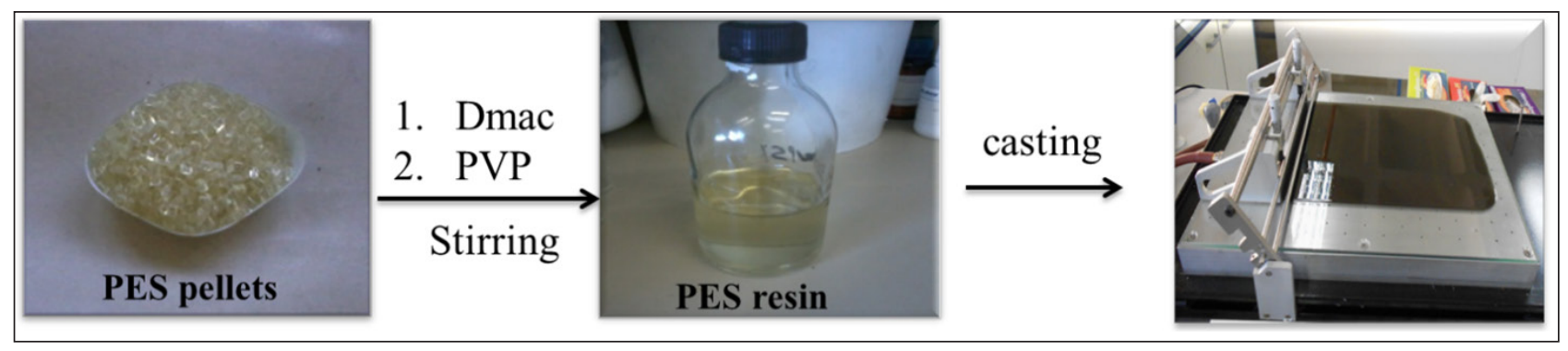

Figure 1

A pictorial presentation of the preparation process for PES membranes supported on the NWFs using the phase inversion process

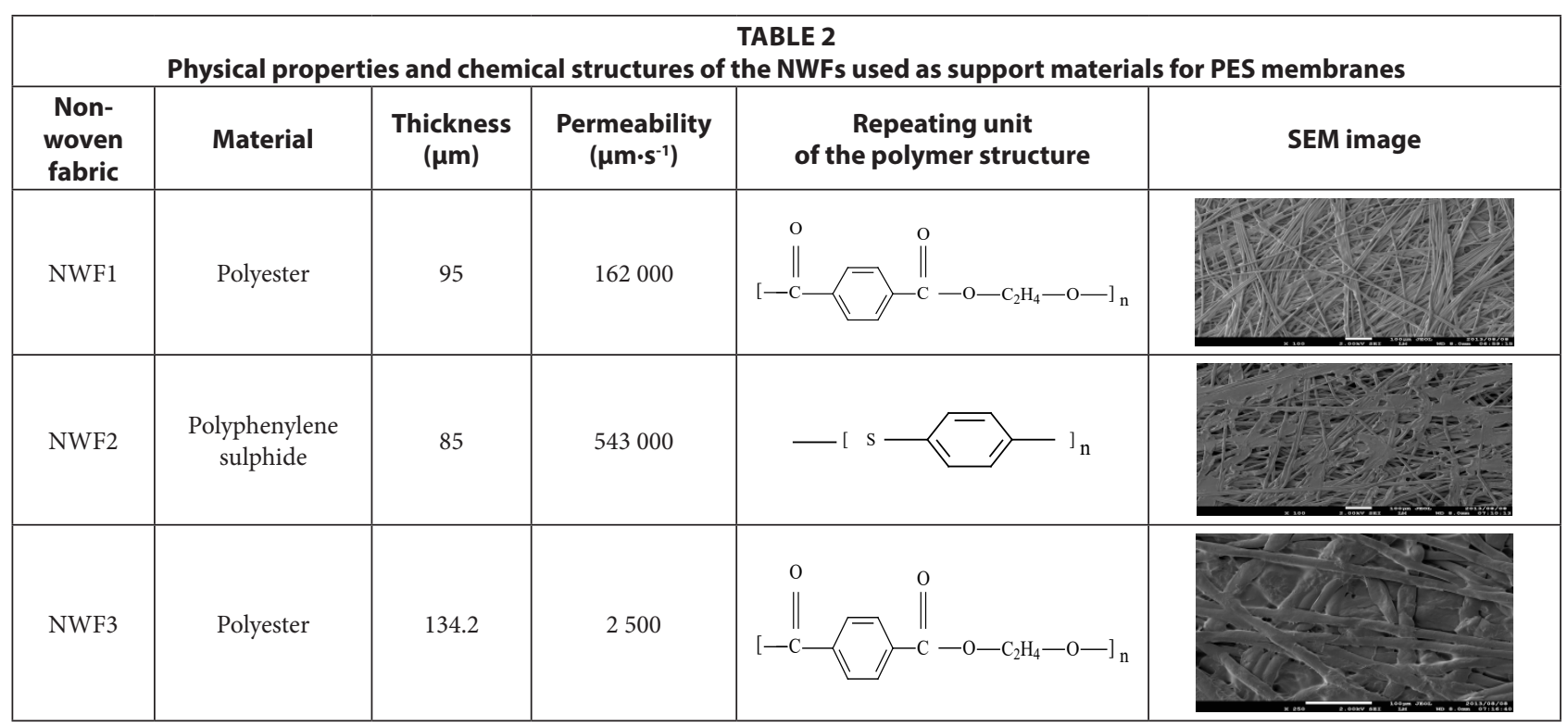

The flux (J) was calculated using Eq. 1.

$J=\frac{V}{A \times t}$

where: $V$ is the permeate volume $(\mathrm{L}), A$ is the membrane effective area $\left(0.001875 \mathrm{~m}^{2}\right)$ and $t$ is the time $(\mathrm{h})$ required for the permeate volume to be collected.

Percentage rejection of HA from the feed solution was calculated using the following equation:

$R(\%)=\frac{C f-C p}{C f} \times 100$

where: $C_{\mathrm{f}}$ is the HA concentration in the feed and $C_{\mathrm{p}}$ represents the HA concentration in the permeate in $\mathrm{mg} \cdot \mathrm{L}^{-1}$.

\section{RESULTS AND DISCUSSION}

\section{FTIR spectroscopy analysis}

The FTIR spectral images of the different PES membranes supported on the NWFs $1-3$ are shown in Fig. 3 (A, B, C). The FTIR spectra of the bare NWFs are also shown in Fig. 3. The PES spectra show a characteristic band at around $\sim 1352 \mathrm{~cm}^{-1}$ which was attributed to the $\mathrm{S}=\mathrm{O}$ stretching vibrations in the PES. The spectra of bare NWF1, NWF2 and NWF3 can be immediately differentiated from the spectra by this band. The strong stretch at $\sim 1250 \mathrm{~cm}^{-1}$ can be assigned to the aromatic ether (Ar-O) stretching vibration of the PES in NWF1 and NWF3. The band at $\sim 1485 \mathrm{~cm}^{-1}$ of PES can be assigned to the aromatic C-C band.

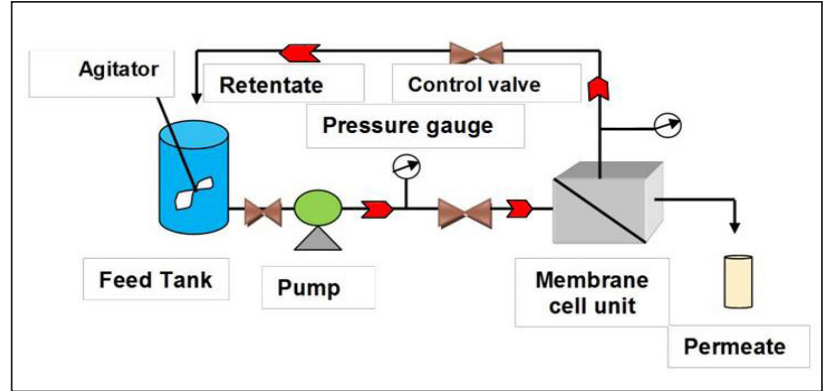

Figure 2

A schematic presentation of the experimental set up of the cross-flow system used in this study

The carbonyl $(\mathrm{C}=\mathrm{O})$ stretching vibration at $\sim 1700 \mathrm{~cm}^{-1}$ can be noted on the FTIR spectra of NWF1 and NWF3, emanating from the pristine polyester support. The peak at $\sim 1620 \mathrm{~cm}^{-1}$ is characteristic of $\mathrm{C}=\mathrm{O}$ stretching vibrations. Its appearance in the spectra was attributed to the presence of PVP in the PES membranes. The peaks observed in this study are comparable to what others have found (Haider et al., 2016; Hanafi et al., 2016; Li et al., 2010).

\section{Contact angle measurements}

Figure 4 shows the contact angles of PES membranes supported on different NWFs. Measurements were repeated at least 10 times and the average reported. Malek et al. (2012) reported the addition of PVP to PES membranes and showed 
that PVP improves the hydrophilicity of the membranes. Indeed, a decrease in contact angle was observed as the concentration of PVP was increased in this work. This is a desired property of the membranes because it suggests that they will demonstrate improved flux and higher resistance to fouling (Malek et al., 2012).

When contact angle measurements were done on the unsupported PES membranes (Fig. 4D), higher values were obtained. This suggests that the NWFs play a role in improving hydrophilic properties of the membranes. However, it cannot be explained at this stage how this occurs since the support was below the active layer (PES layer). The incorporation of PVP had a similar effect on the NWF supported membranes. The hydrophilicity of the supported membranes was attributed to the $\mathrm{N}-\mathrm{C}=\mathrm{O}$ functional group present in PVP which interacted with the more polar functional group $(\mathrm{O}=\mathrm{S}=\mathrm{O})$ present in the PES membranes. The presence of $\mathrm{C}=\mathrm{O}$ and $\mathrm{O}=\mathrm{S}=\mathrm{O}$ were also confirmed by the FTIR results. This interaction can involve a donor/acceptor mode of interaction between $\mathrm{N}-\mathrm{C}=\mathrm{O}$ and the aromatic ring of PES membrane (Vatsha et al., 2014).

\section{Thermogravimetric studies}

The TGA profiles of the NWFs, pristine NWF/PES and NWF/ PES/PVP membranes are shown in Fig. 5 a, b, and c. The NWFs were less thermally stable compared to the PES/NWF membranes. Their thermal decomposition occurred at temperatures below the decomposition temperatures of the PES membranes. NWF1 and NWF3 exhibited a lower decomposition temperature, of $446^{\circ} \mathrm{C}$, compared to NWF2 which decomposed at $452^{\circ} \mathrm{C}$. The differences in decomposition behaviour were attributed to the activation energies of the different repeating unit of the polymer. The phenyl to sulphur bond of the polyphenylene sulphide (PPS) requires more energy than the phenyl to carbon bond of the polyester; as a consequence the latter is less thermally stable. The TGA profiles of the NWFs are distinct from the rest of the PES/NWF profiles. The addition of PVP to the membranes had an insignificant effect on membrane thermal stability. The TGA profiles of the PES/5wt\% PVP membranes, despite the NWF used, showed greater thermal stability compared to membranes whose additive concentration was greater. The membranes supported on NWF2 exhibited a higher degradation temperature, at $600^{\circ} \mathrm{C}$, which shows that they have the highest thermal stability. This could be attributed to the energy required to break the bonds of both the PPS support as well as the PES/PVP membrane. In general, these materials are thermally stable and can be used where boiling conditions exist, e.g., in distillation membranes.

\section{SEM analysis}

SEM surface and cross-sectional morphologies of the PES/ NWF membranes are given in Fig. $6(a, b, c)$. The crosssections were taken at $1500 \mathrm{X}$ magnification, whilst surface images were taken at various magnifications to the best of the SEM resolution. Bare PES membranes can be overtly distinguished from the NWF-supported membranes with PVP additive by virtue of their orientation, size and asymmetric properties. The surface of the membranes became rougher with the addition of PVP. AFM studies were conducted to confirm this observation (refer to AFM analysis section).

The effect of PVP addition on the pore sizes at the surface and cross-section of the modified membranes was also observed under SEM analysis. As the concentration of the
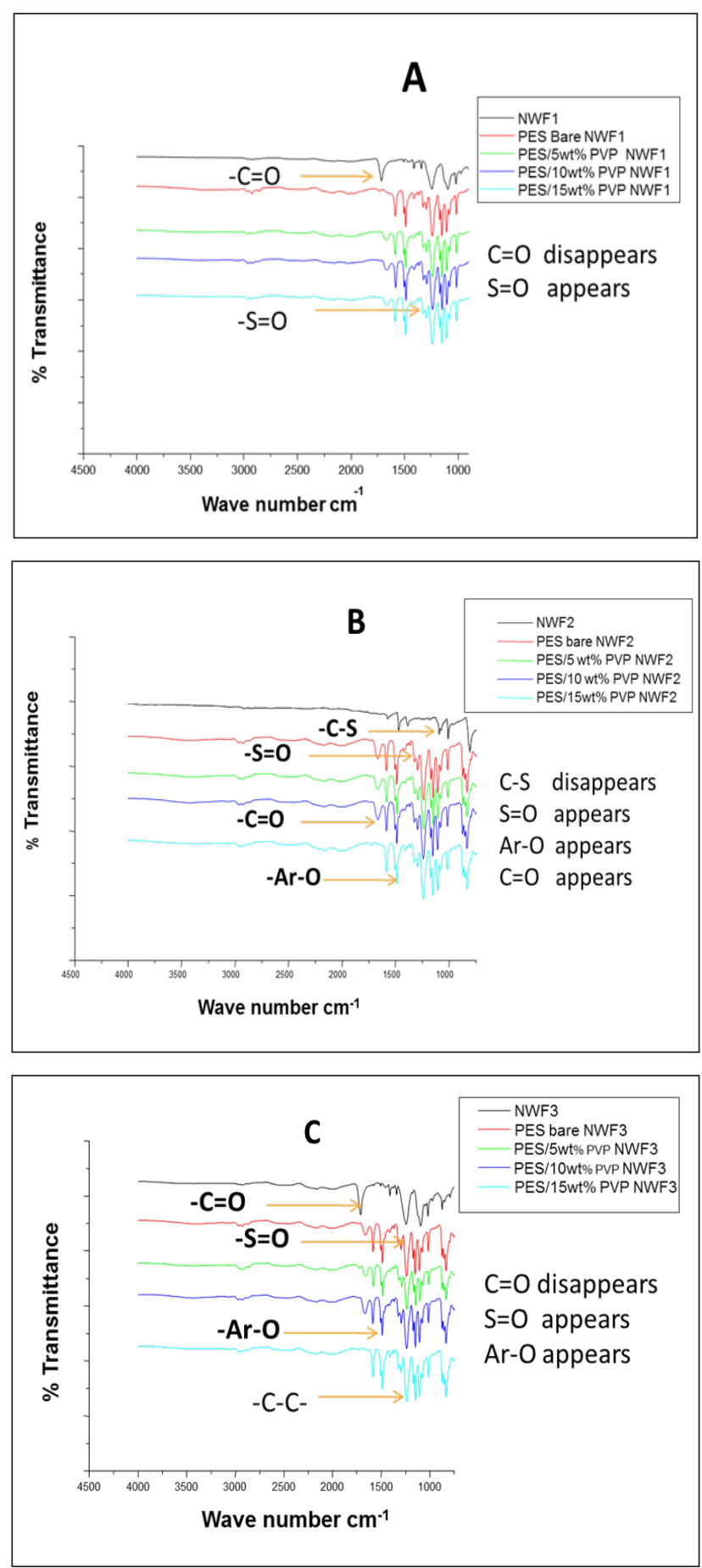

Figure 3

FTIR spectra of PES membranes supported on NWF1, NWF2 and NWF3

PVP was increased, the pore sizes at the surface of the membranes also increased. Similarly, the finger-like pores on the membrane cross-section became bigger whilst becoming more asymmetric compared to the relatively small finger-like pores in the bare membranes. Thus, we observed that the pore sizes at the surface of the membranes were much smaller than the macrovoids that exist in the range 3-4 $\mu \mathrm{m}$ beneath the surface of the membrane. Figure 7 shows average pore size graphs of the surface and macrovoids (cross-sectional pores) of the PES and NWF/PES membranes. It can be observed that the macrovoids are vertical to the membrane surface. This orientation should allow improved water flux across the membrane. There 

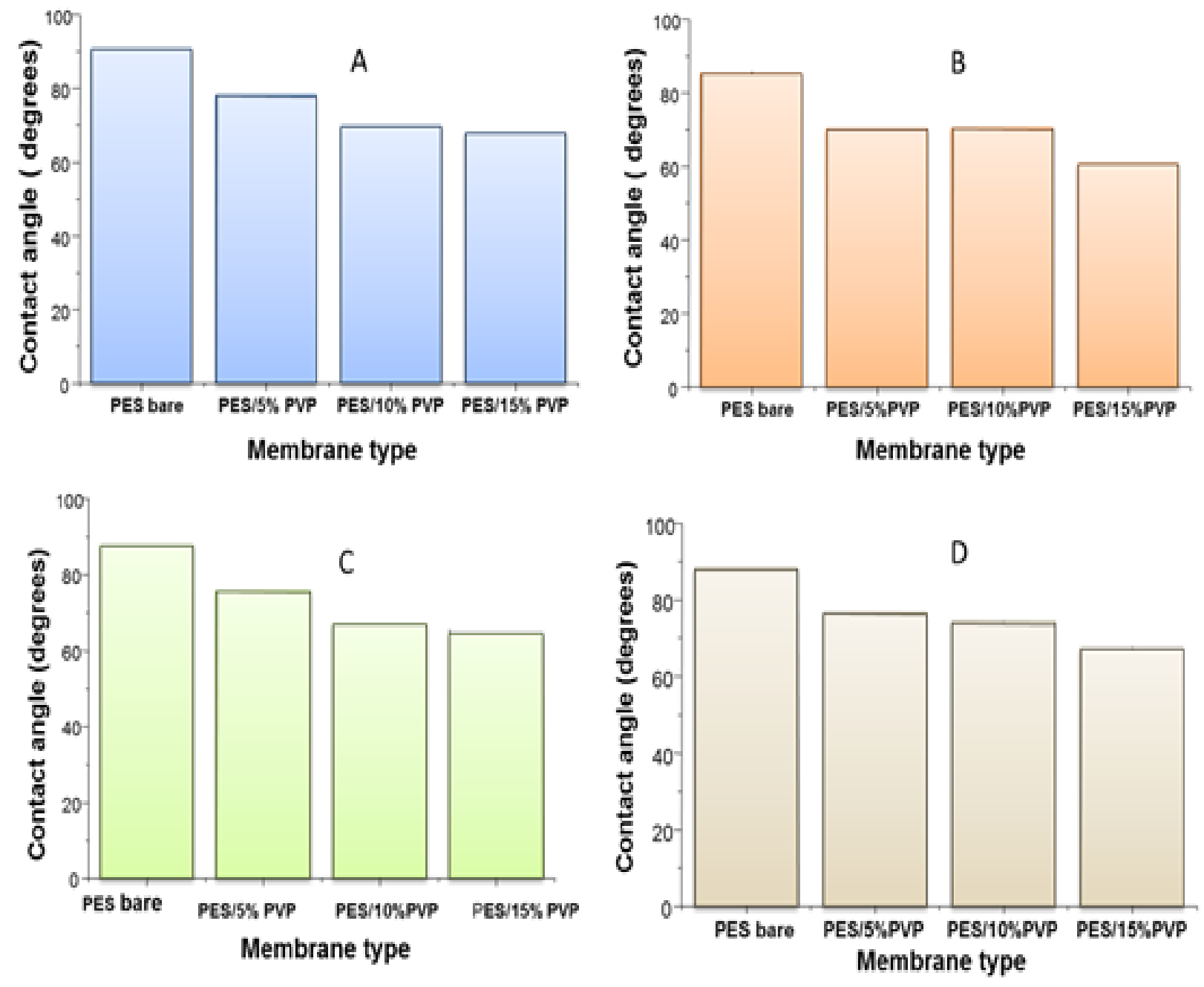

Figure 4

Surface water contact angles for PES membranes supported on NWF1 (A) NWF2 (B), NWF3 (C) and unsupported PES membranes (D)

was no clear correlation between the type of NWF support used and the pore sizes obtained. The use of the NWF supports did not have any effect on the cross-sectional morphology of the membranes and no distinct macrovoids could be classified as characteristic of a particular NWF.

Image J software was used to estimate the average pore sizes of the membranes. As can be seen from Fig. 7, comparison of the surface pore sizes in Fig. 7a of NWF1 and NWF3 showed that there were significant differences in the pore sizes. The porosity differences between the two supports could have caused this. The results were, however, not conclusive because this trend was not observed with the cross-sectional dimensions in Fig. 7b. As such our interest was focused on how these observed properties would affect the membrane behaviour during water purification.

\section{AFM analysis}

Figures 8-10 show 3-D AFM images of pristine PES membranes (a) and membranes modified with PVP (b, c, d) supported on the NWFs. The membrane surface morphology changed variably as the concentration of PVP was incrementally varied. Tables $3-5$ present the surface roughness of the membranes, where $R a$ is the mean roughness of the membranes, while $R q$ is the root mean square roughness. The pristine PES membranes gave higher $R a$ values across all membrane supports. However, the $R a$ values decreased with addition of PVP, which indicates a decrease in membrane surface roughness. The observation is in agreement with the declining contact angle values attained, indicative of the increase in hydrophilicity. This observation was constant for PES membranes supported on NWF1 fabric. However, membranes supported on NWF2 and NWF3 exhibited a decreasing trend in roughness, but as the concentration of PVP increased further, membrane roughness also increased until a concentration preceding the maximum PVP concentration. Therefore at $10 \mathrm{wt} \% \mathrm{PVP}$, the $R a$ values decreased again, which meant that the membrane surface was becoming less rough again. Some reasons for this could be the following: (i) increase in permeability of the membrane with PVP addition (Adams et al., 2012) and (ii) the change in roughness is in proportion to the membrane pore size as already discussed in the SEM section and follows from the discussion of this by other workers (Peyravi et al., 2012). Thus the AFM results obtained in this present study confirm the link between membrane porosity and the surface roughness. 

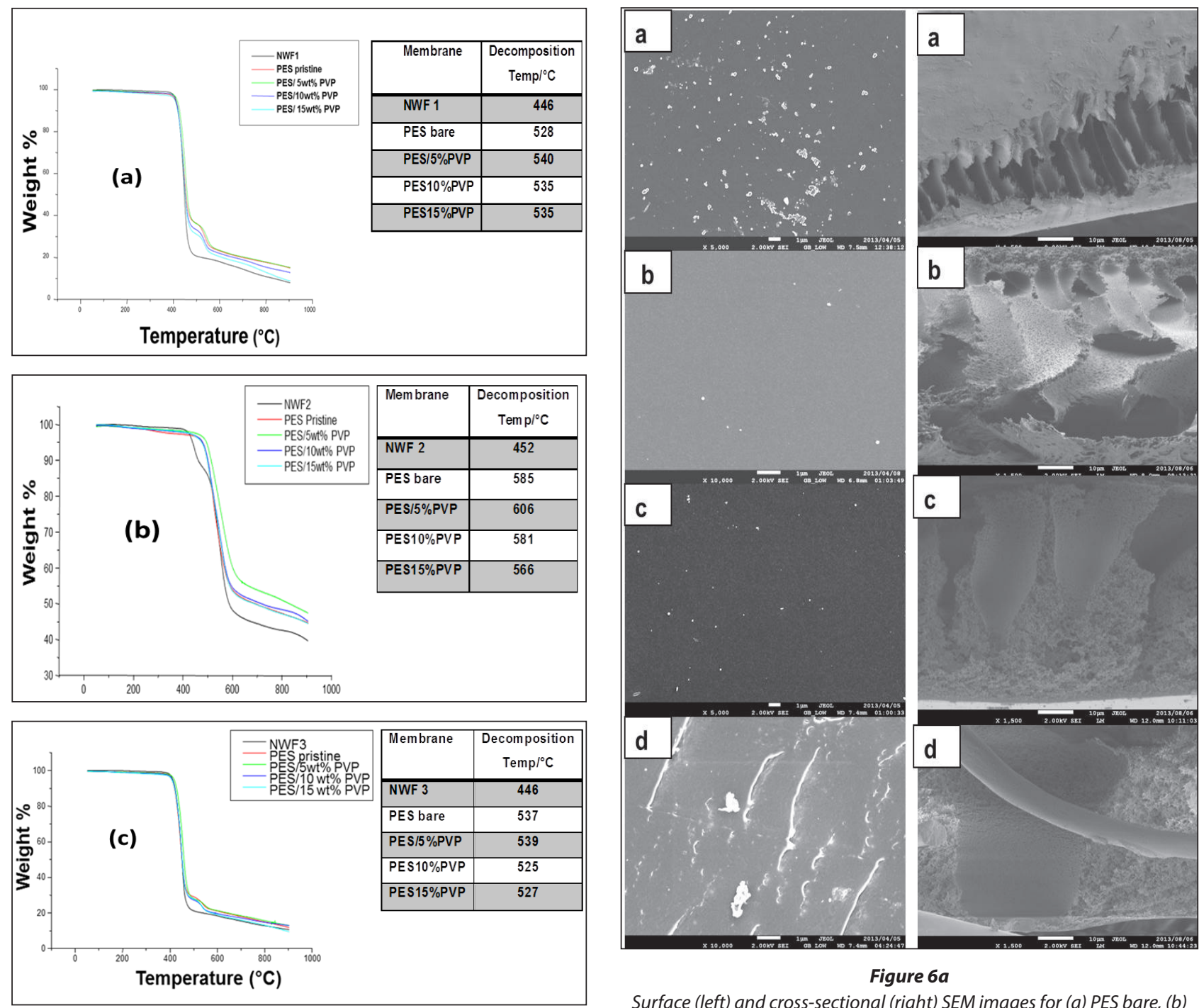

Figure 5

TGA profiles of hand-cast PES membranes supported on (a) NWF1, (b) NWF2 and (c) NWF3

Figure 6a

Surface (left) and cross-sectional (right) SEM images for (a) PES bare, (b) PES $/ 5 w t \%$ PVP, (c) PES $/ 10 w t \%$ PVP and (d) PES $/ 15 w t \%$ PVP membranes supported on NWF1. The rod-like feature in d (right) is part of the supporting NWF layer

TABLE 3

\begin{tabular}{|c|c|c|c|c|}
\hline \multicolumn{5}{|c|}{ TABLE 3 } \\
AFM surface roughness values of PES membrane and PES/PVP membranes supported on NWF1
\end{tabular}

TABLE 4

\begin{tabular}{|c|c|c|c|c|}
\hline \multicolumn{5}{|c|}{ TABLE 4 } \\
\hline \multirow{2}{*}{ Parameter } & PES bare & $\begin{array}{c}\text { PES 5 wt\% } \\
\text { PVP }\end{array}$ & $\begin{array}{c}\text { PES 10 wt\% } \\
\text { PVP }\end{array}$ & $\begin{array}{c}\text { PES 15 wt \% } \\
\text { PVP }\end{array}$ \\
\hline$R a$ & $25.203 \mathrm{~nm}$ & $14.029 \mathrm{~nm}$ & 56.744 & $7.601 \mathrm{~nm}$ \\
\hline$R q$ & $38.776 \mathrm{~nm}$ & $18.206 \mathrm{~nm}$ & 75.608 & $9.045 \mathrm{~nm}$ \\
\hline
\end{tabular}

TABLE 5

\begin{tabular}{|c|c|c|c|c|}
\hline \multicolumn{5}{|c|}{ TABLE 5 } \\
AFM surface roughness values of PES membrane and PES/PVP membranes supported on NWF3
\end{tabular}




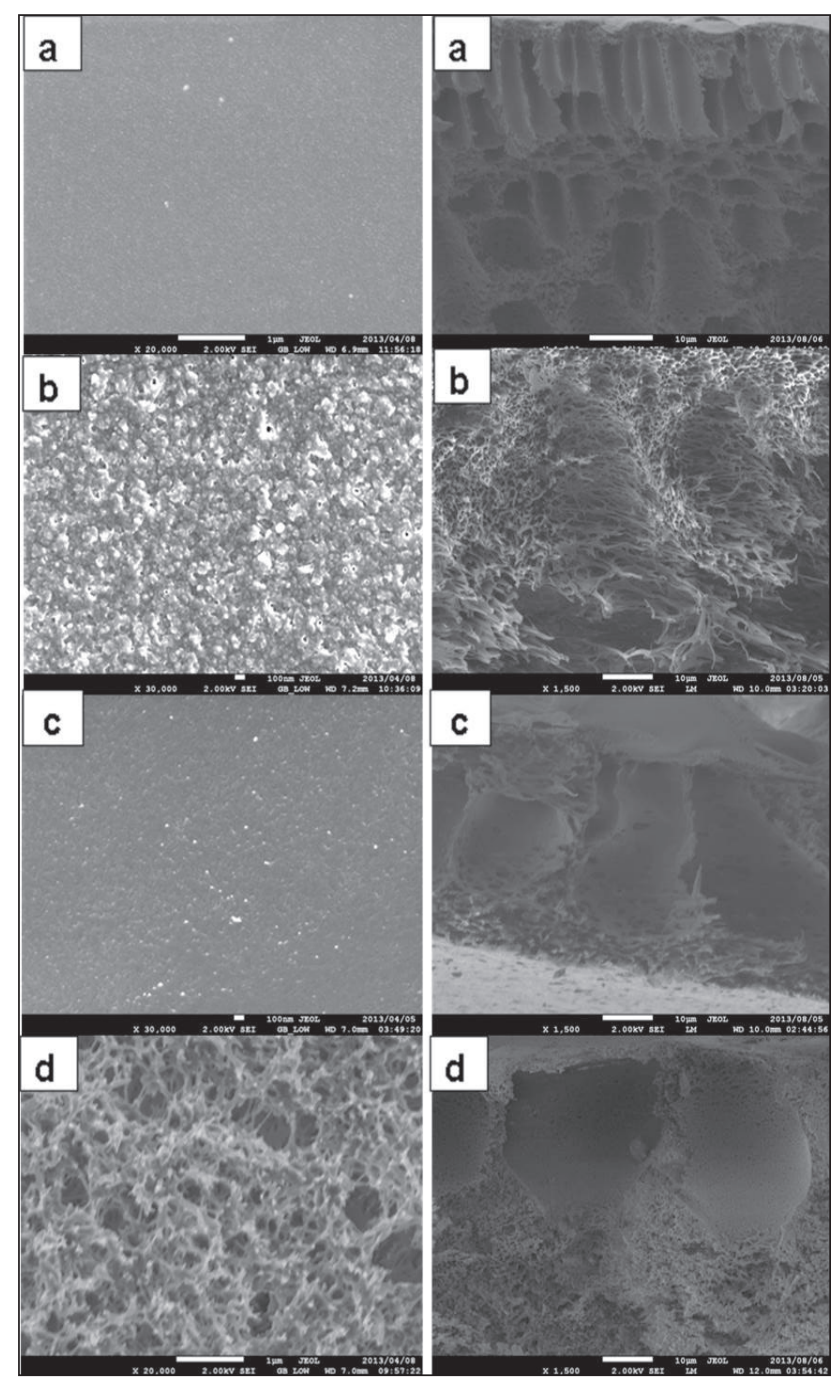

Figure $6 b$

Surface (left) and cross-sectional (right) SEM images for (a) PES bare (b) PES/5wt\% PVP, (c) PES/10wt\% PVP and (d) PES/15wt\% PVP membranes supported on NWF2

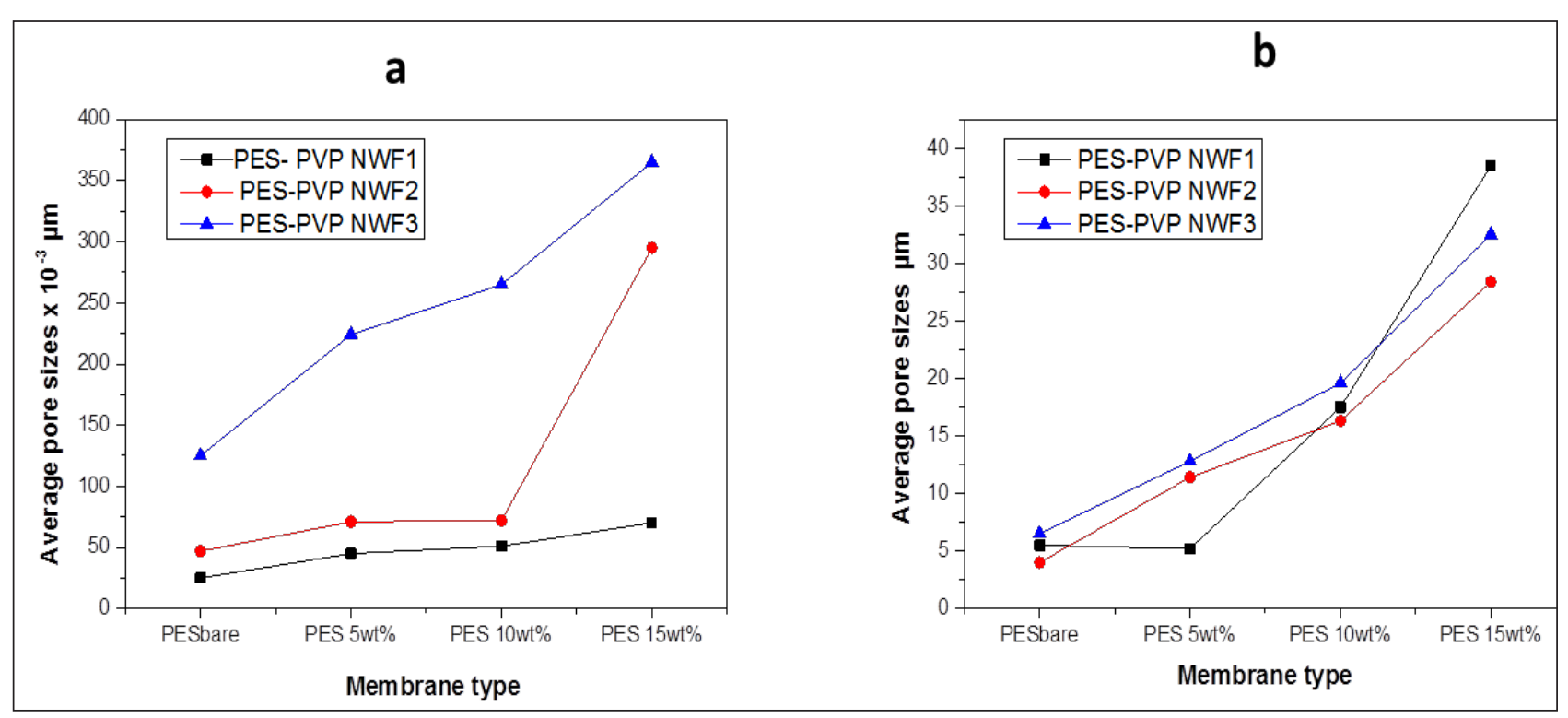

Figure 7

The average pore sizes of the membrane surfaces (a) and cross-sections (b)

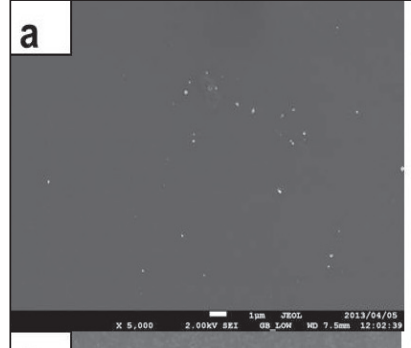

\section{b}
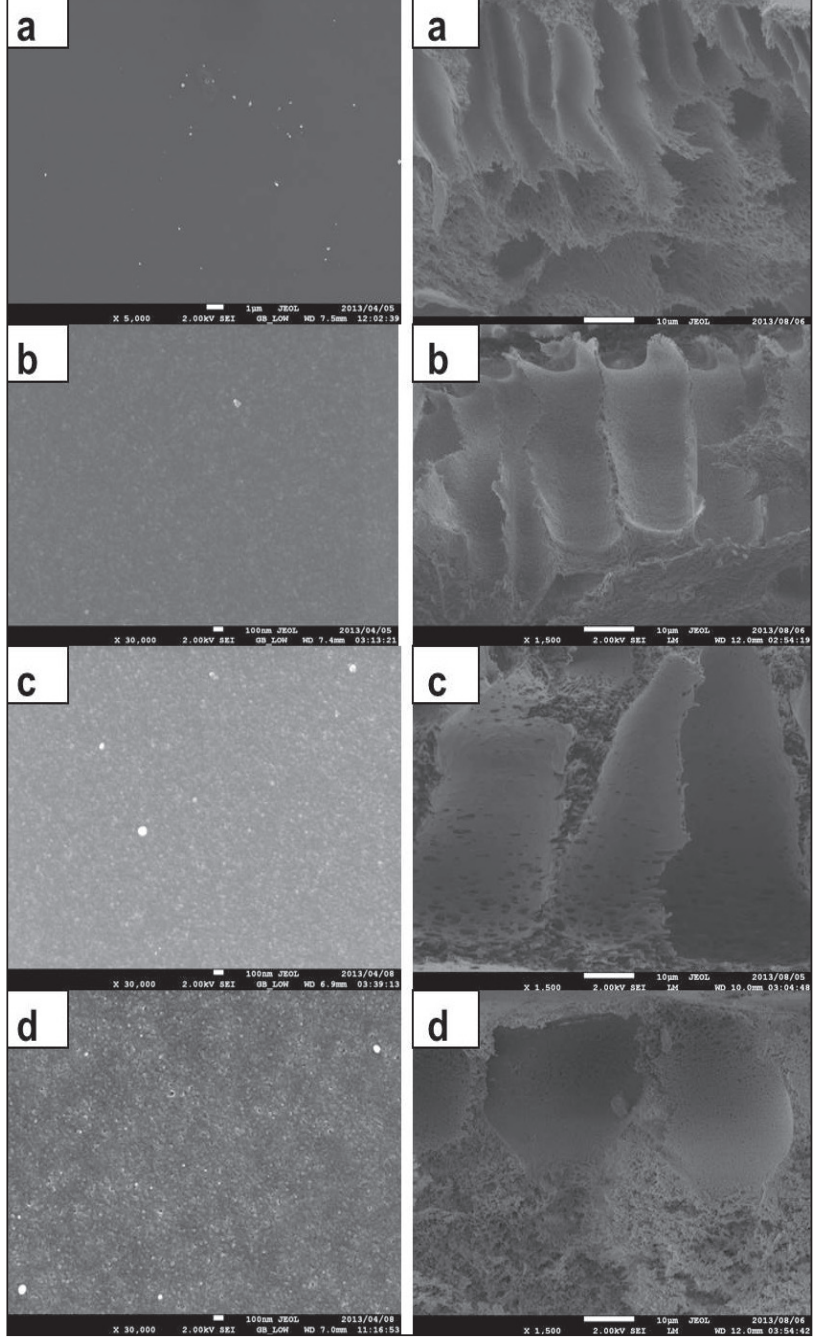

Figure 6c

Surface (left) and cross-sectional (right) SEM images for (a) PES bare (b) PES/5wt\% PVP, (c) PES/10wt\% PVP and (d) PES/15wt\% PVP membranes supported on NWF3 


\section{Mechanical properties of the PVP/PES membranes}

The tensile strength values of the PVP/PES supported and PVP/ PES unsupported membranes are given in Table 6. It can be seen that adding PVP to PES resulted in a decrease in the tensile strength of the resulting membranes. To counteract this loss in mechanical strength, we used the NWFs to support the PVPmodified membranes. The result was a significant increase in the overall tensile strength. The strength was more than 3 -fold and the performance of the membranes was not compromised and is shown in the section on membrane application.

The tensile strength of these membranes was compared with those of carbon nanotube (CNT) enhanced PES membranes synthesized by Phao et al. (2013). The PES membranes containing small amounts of N-CNTs possessed improved mechanical strength due to the inherent properties of the CNTs. However, it is likely that these membranes will lose some strength upon modification. It may be necessary to support these membranes, especially if high pressure is required to clean them or increase water flux across their pores.

\section{Membrane application}

\section{Pure water membrane flux}

The flux values of pure water across the membranes are shown in Fig. 11(a, b, c). A significant increase in flux was observed with an increase in PVP concentration. High flux was observed with the PES/15wt\% PVP membranes with the highest observed when this membrane was supported on NWF2. This correlated with the large pores (shown by SEM images) observed for these membranes which allowed water to flow with ease across the membranes. The increase in flux was due to the improvement in membrane porosity and hydrophilicity (Jamshidi Gohari et al., 2013). The membrane flux trend was consistent with the viscosity of the casting solution, since the formation of the membrane is related to the viscosity of the original polymer solution (Zinadini et al., 2014). The pure water flux results suggest that membranes with different supports showed no difficulty in achieving an optimum flux that was stable, thus rendering these membranes usable at very low pressures. The membranes supported on NWF2 showed much greater fluxes when compared to PES membranes supported on NWF1 and NWF3. The difference in flux could be attributed to the very high permeability of NWF2, as outlined in Table 1.

\section{HA flux and rejection studies}

HA fouling studies performed on the PES/PVP membranes supported on NWFs revealed the importance of incorporating the PVP additive to improve antifouling properties. To study the fouling behaviour of the membranes, a relationship between relative flux $J / J_{0}$ and initial flux was used (Akar et al., 2013), where $J /$ $J_{0}$ values were plotted against time as depicted in Fig. 12. These experiments were conducted at a pressure of $137.9 \mathrm{kPa}$. The membranes supported on NWF1 possessed greater antifouling properties compared to membranes supported on NWF2 and NWF3. The resistance to fouling, however, was not consistent for all the membranes with the incremental incorporation of PVP. The bare PES/NWF1 and bare PES/NWF3 membranes showed greater antifouling propensity compared to the PVPmodified membranes. Bare PES/NWF2 showed a higher fouling propensity. However, for the NWF2-supported PES membranes,
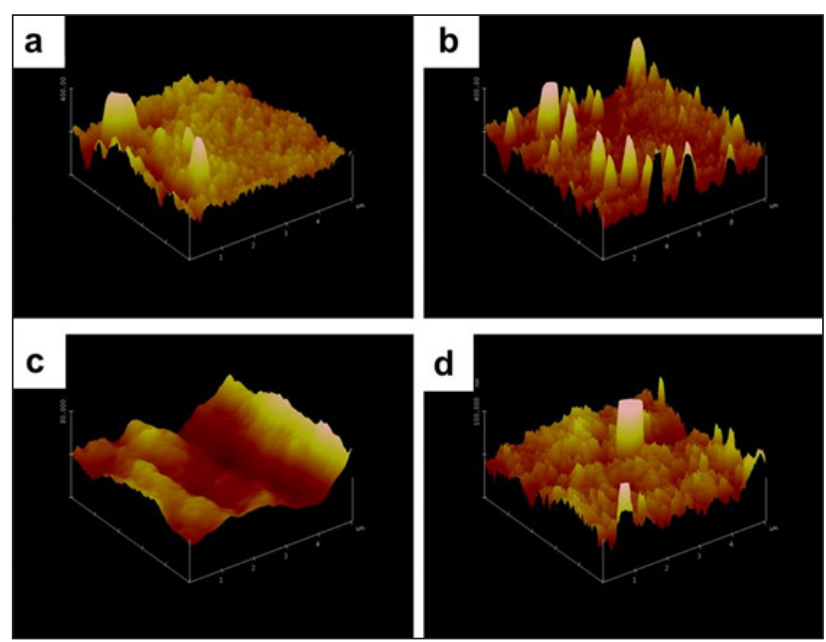

Figure 8

AFM images for PES bare (a), PES $5 w t \%$ PVP (b), PES $10 w t \%$ PVP (c) and PES $15 w t \%$ PVP (d) supported on NWF1
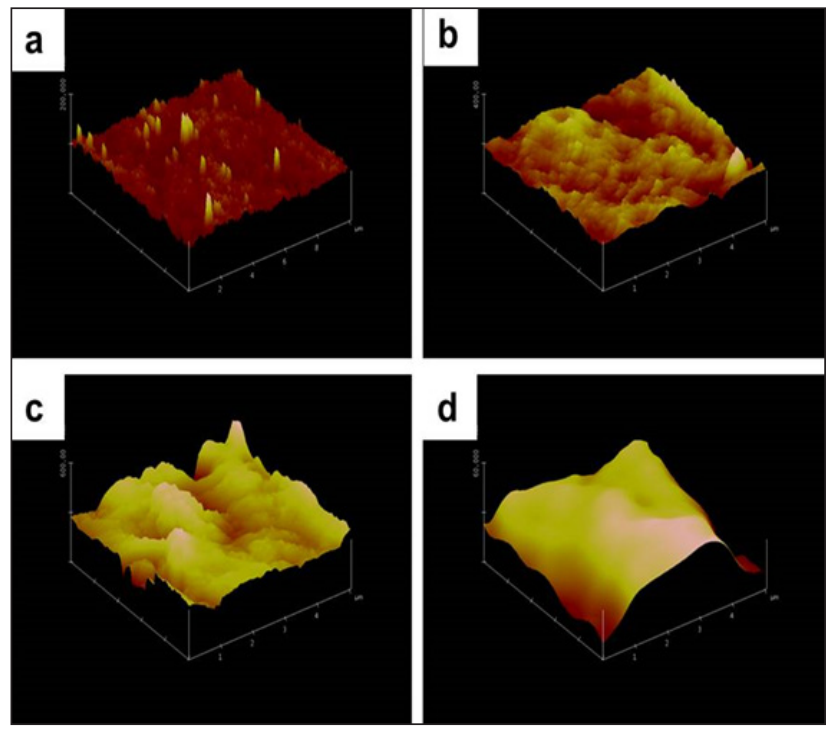

Figure 9

AFM images for PES bare (a), PES 5wt\% PVP (b), PES 10wt\% PVP (c) and PES 15wt\% PVP $(d)$ supported on NWF2
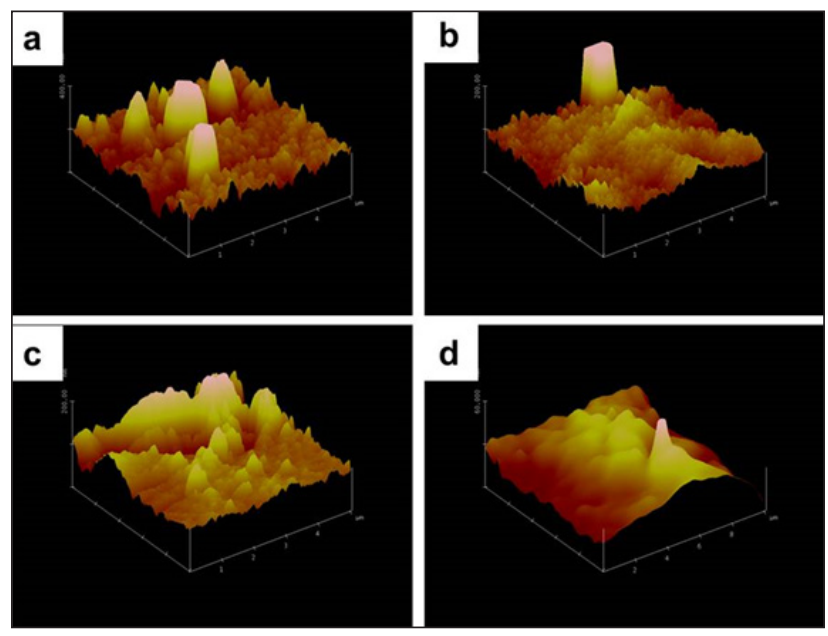

Figure 10

AFM images for PES bare (a), PES 5wt\% PVP (b), PES 10wt\% PVP (c) and PES $15 w t \%$ PVP $(d)$ supported on NWF3 


\begin{tabular}{|c|c|c|}
\hline \multicolumn{3}{|c|}{$\begin{array}{c}\text { Table } 6 \\
\text { Tensile strength values of PVP modified PES membranes; unsupported and supported on NWFs }\end{array}$} \\
\hline \multirow{2}{*}{ Membrane } & \multicolumn{2}{|c|}{ Tensile strength (MPa) } \\
\hline & *Unsupported & Supported on NWF1 \\
\hline PES & 3.7 & 8.5 \\
\hline 5\%PVP/PES & 2.8 & 7.6 \\
\hline 10\%PVP/PES & 2.5 & 7.3 \\
\hline 15\%PVP/PES & 2.1 & 7.2 \\
\hline $0.04 \% \mathrm{~N}-\mathrm{CNTs} / \mathrm{PES}^{*}$ & 4.4 & - \\
\hline $0.5 \% \mathrm{~N}-\mathrm{CNTs} / \mathrm{PES}^{*}$ & 3.2 & - \\
\hline
\end{tabular}

${ }^{*}$ These membranes were prepared in a separate study using the same method and are presented here for comparison (Phao et al., 2013)
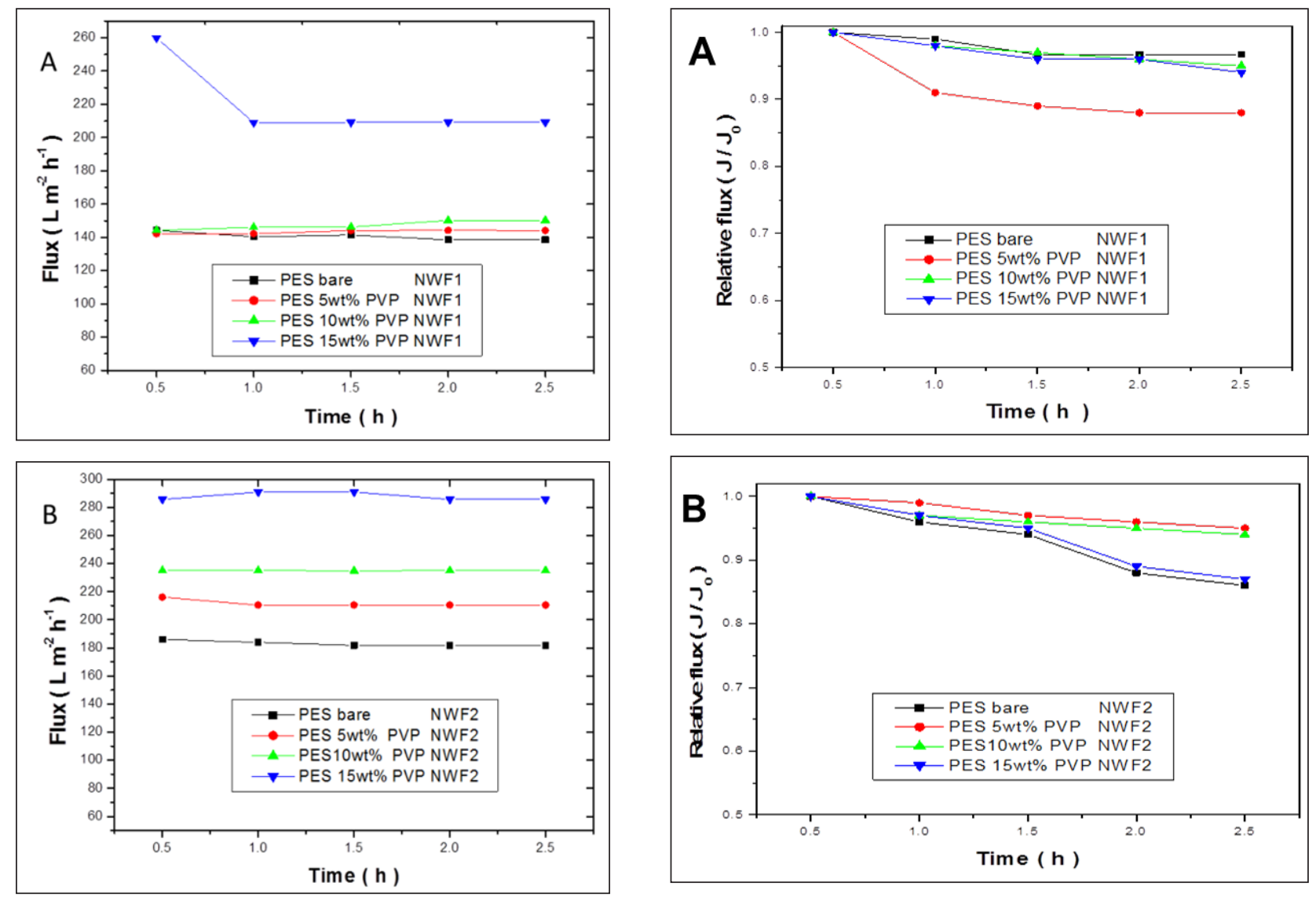

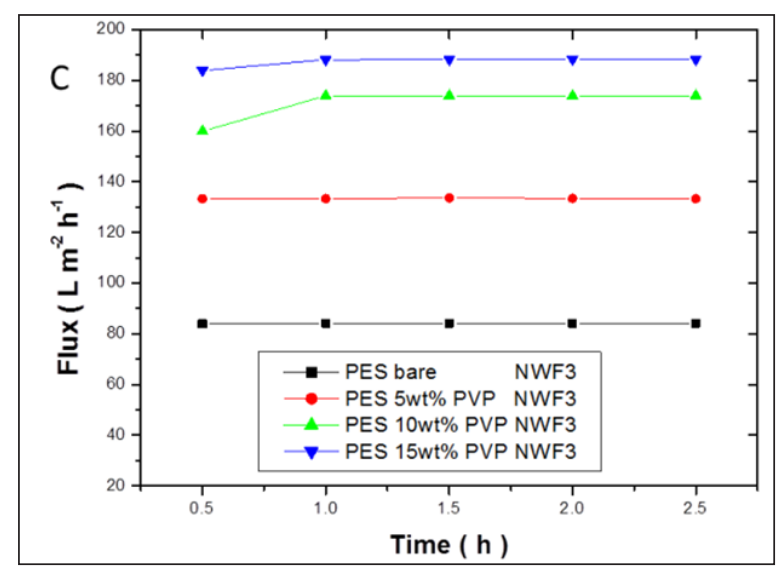

Figure 11

Flux versus time graphs for PES membranes supported on NWF1 (a), NWF2 (b) and NWF3 (c)

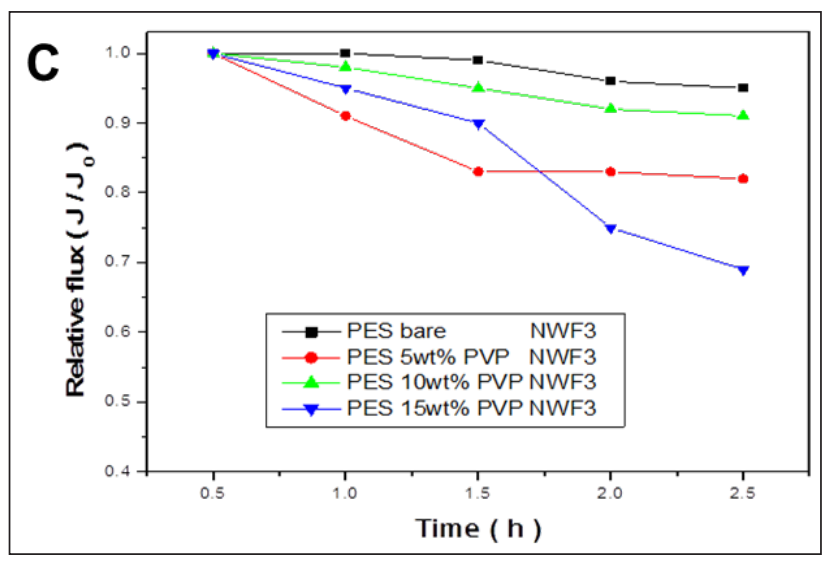

Figure 12

Relative flux versus time graphs for PES membranes supported on NWF1 (a), NWF2 (b) and NWF3 (c) 
fouling increased with an increase in PVP concentration. This trend agrees with the pure water flux results, where flux was observed to increase with increase in PVP concentration. Thus, membranes supported on NWF1 and NWF2 exhibited better antifouling properties compared to NWF3.

An improvement in the membranes' antifouling properties seemed to be inherently dependent on the manner in which the membranes were fabricated. The membrane fouling tendencies were observed to be dependent on the surface roughness of the membranes as observed from AFM results, where membranes with rougher surfaces appear to have a higher propensity for fouling. This observation was also noted by Riedl et al. (1998). These rougher membranes have an ability to produce a fouling surface layer that is loose, capable of a low fouling resistance per unit thickness of the foulant layer. The membranes with smooth surfaces were found to have a thicker layer due to fouling by HA, which was consequently attributed to their tendency to experience fouling (Mehrparvar et al., 2014).

This study was also concerned with ascertaining which NWF furnishes the membranes with better antifouling properties, as PVP concentration was varied with respect to PES. The results have demonstrated that both NWF1 and NWF2 exhibited better antifouling properties compared to membranes supported on NWF3.

Figure 13 shows the HA rejection results for the PES membranes supported on NWF1, NWF2 and NWF3. The membranes supported on NWF1 showed high rejections of the HA pollutant. This is due to the smaller pore sizes of the membranes (see Fig. 7). The size of a HA molecule ranges between 1600 and $20000 \mathrm{~g} \cdot \mathrm{mol}^{-1}$ (Wang et al., 2009). The maximum HA rejection values attained for the PES membranes supported on NWF1 were between $96.5 \%$ and $98 \%$ compared to $69 \%$ and

TABLE 7

Pure water flux and rejections of membranes supported on different NWFs (applied pressure $=137.9 \mathrm{kPa}$ )

\begin{tabular}{|c|c|c|c|c|c|c|c|c|}
\hline $\begin{array}{c}\text { Membrane } \\
\text { NWF1 }\end{array}$ & $\begin{array}{c}\text { Flux } \\
\left(L \cdot m^{-2} \cdot h^{-1}\right)\end{array}$ & $\begin{array}{l}\text { Rejection } \\
(\%)\end{array}$ & \begin{tabular}{|c|}
$\begin{array}{c}\text { Membrane } \\
\text { NWF2 }\end{array}$ \\
\end{tabular} & $\begin{array}{c}\text { Flux } \\
\left(L \cdot \mathbf{m}^{-2} \cdot \mathbf{h}^{-1}\right)\end{array}$ & $\begin{array}{l}\text { Rejection } \\
(\%)\end{array}$ & $\begin{array}{c}\text { Membrane } \\
\text { NWF3 }\end{array}$ & $\begin{array}{c}\text { Flux } \\
\left(\mathbf{L} \cdot \mathbf{m}^{-2} \cdot \mathbf{h}^{-1}\right) \\
\end{array}$ & $\begin{array}{c}\text { Rejection } \\
(\%)\end{array}$ \\
\hline PES bare & 140 & 96.5 & PES bare & 85 & 90 & PES bare & 85 & 77 \\
\hline $\begin{array}{l}\text { PES } 5 \text { wt } \% \\
\text { PVP }\end{array}$ & 145 & 98 & $\begin{array}{l}\text { PES } 5 \text { wt } \% \\
\text { PVP }\end{array}$ & 130 & 92.5 & $\begin{array}{l}\text { PES } 5 \text { wt } \% \\
\text { PVP }\end{array}$ & 130 & 82.5 \\
\hline $\begin{array}{l}\text { PES } 10 \text { wt } \% \\
\text { PVP }\end{array}$ & 155 & 97 & $\begin{array}{l}\text { PES } 10 \mathrm{wt} \% \\
\text { PVP }\end{array}$ & 170 & 92.5 & $\begin{array}{l}\text { PES } 10 \text { wt } \% \\
\text { PVP }\end{array}$ & 169 & 78 \\
\hline $\begin{array}{l}\text { PES } 15 \text { wt } \% \\
\text { PVP }\end{array}$ & 210 & 97.5 & $\begin{array}{l}\text { PES } 15 \text { wt } \% \\
\text { PVP }\end{array}$ & 188 & 70 & $\begin{array}{l}\text { PES } 15 \text { wt } \% \\
\text { PVP }\end{array}$ & 190 & 97.5 \\
\hline
\end{tabular}

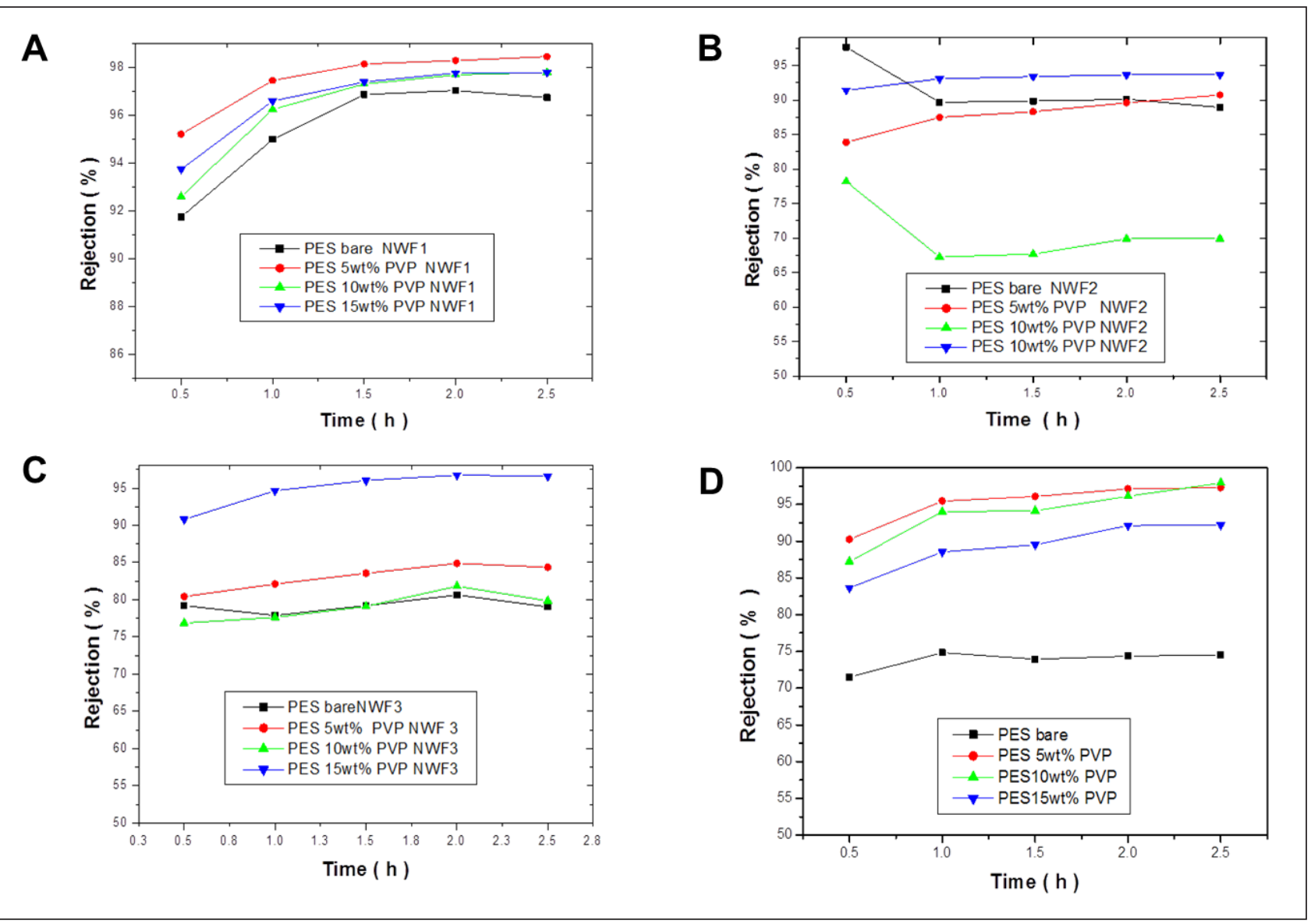

Figure 13

HA rejection for (a), PES/PVP/NWF1, (b) PES/PVP/NWF2, (c) PES/PVP/NWF3 and (d) PES unsupported membranes 
96\%, respectively, for the NWF2- and NWF3-supported PES membranes. As expected, the incorporation of PVP as a pore former and hydrophilicity enhancer does not consistently produce high HA rejection but improves the flux. The PES/15wt\% PVP supported on NWF2 and PES/15wt\% supported on NWF3 membranes were found to follow the trend of high rejection whenever a high concentration of PVP was incorporated.

Unsupported PES/PVP membranes gave rejections that were comparable to some of the supported membranes. Their rejections ranged between $72 \%$ and $96 \%$. These values were similar to the results obtained for membranes supported on NWF2 and NWF3, respectively. Membranes supported on NWF1 gave exceptionally high rejections, with $98 \%$ the highest value attained, compared to rejections attained for unsupported membranes. The results show the importance of incorporating non-woven supports as a means of pollutant rejection improvement.

The membrane pure water flux was observed to increase with PVP loading. The PES 15wt\% PVP membranes supported on NWF1 gave an average flux of $210 \mathrm{~L} \cdot \mathrm{m}^{-2} \mathrm{~h}^{-1}$, which was the highest flux obtained in this work. A comparison with other membranes revealed that the difference in flux was attributed to different properties of the NWF used (see Table 2). Other workers have reported a permeate flux of up to $47.6 \mathrm{~L} \cdot \mathrm{m}^{-2} \mathrm{~h}^{-1}$ when a PVDF membrane was supported on a PET NWF (Hou et al., 2012). Table 7 shows that the flux values for the various membranes are within the range of flux values presented in the literature (see also Table 1). However, the membrane rejections obtained in the present work were higher than those reported in literature. The use of NWFs and the interactions they endow the membranes with are attributed with the high values for NOM rejection, especially for those membranes supported on NWF 1. In addition, membranes with high loading of PVP gave high rejections. Therefore it can be concluded that immobilising polymeric membranes on NWFs has noticeable effects on the membrane rejection abilities, especially when NWF1 was used.

\section{CONCLUSION}

The study was concerned with the fabrication of PES/PVP UF membranes supported on non-woven porous fabrics. The results have shown that NWF-supported membranes reject HA molecules better than unsupported PES membranes. The enhanced performance confirmed that the supporting materials (NWFs) assist in decreasing membrane fouling. The synthesised UF membranes supported on NWF1 gave high rejection percentages (98\%). The increase in water permeation across the membranes was noticeable upon the incremental incorporation of the PVP additive from 5-15 wt\%. SEM results showed a distinction in terms of size between the pores on the membrane surface and those present within the membrane. This had a direct influence on the characteristic flux exhibited by the membranes. SEM further showed that the pores of the membranes increased with increase in PVP concentration, whilst contact angle results revealed that the hydrophilicity of the membranes was enhanced. This was further confirmed by the decrease in membrane roughness as shown by the AFM results. Most importantly this study has demonstrated that these modified PES membranes supported on NWFs are resistant to fouling by NOM (humic acid). The NWFs not only act as a support but provide the mechanical strength required for robust membranes with desired surface properties.

\section{ACKNOWLEDGEMENTS}

The authors would like to thank the DST/Mintek

Nanotechnology Innovation Centre, the NRF Nanotechnology Flagship Project (Grant number (UID): 97823), the DST/IBSA Nanotechnology Flagship Project on Water and the University of South Africa (UNISA) for financial support.

\section{REFERENCES}

ADAMS FV, NXUMALO EN, KRAUSE RWM, HOEK EMV and MAMBA BB (2012) Preparation and characterization of polysulfone/cyclodextrin polyurethane composite nanofiltration membranes. J. Membr. Sci. 405-406 291-299. http://dx.doi. org/10.1016/j.memsci.2012.03.023

AKAR N, ASAR B, DIZGE N and KOYUNCU I (2013) Investigation of characterization and biofouling properties of PES membrane containing selenium and copper nanoparticles. J. Membr. Sci. 437 216-226. http://dx.doi.org/10.1016/j.memsci.2013.02.012

CHANG H, LIANG H, QU F, MA J, REN N and LI G (2015) Towards a better hydraulic cleaning strategy for ultrafiltration membrane fouling by humic acid: Effect of backwash water composition. J. Environ. Sci. 43 177-186. http://dx.doi.org/10.1016/j. jes.2015.09.005

DOMANY Z, GALAMBOS I, VATAI G and BEKASSY-MOLNAR E (2002) Humic substances removal from drinking water by membrane filtration. Desalination 145 333-337. http://dx.doi. org/10.1016/S0011-9164(02)00432-0

ELIMELECH M and PHILLIP WA (2011) The future of seawater desalination: energy, technology, and the environment. Science 333 (6043) 712-717. http://dx.doi.org/10.1126/science.1200488

FAN Z, GONG S, XU X, ZHANG X, ZHANG Y and YU X (2014) Characterization, DBPs formation, and mutagenicity of different organic matter fractions in two source waters. Int. J. Hyg. Environ. Health 217 300-306. http://dx.doi.org/10.1016/j.ijheh.2013.07.002

HAIDER M S, SHAO GN, IMRAN SM, PARK SS, ABBAS N, TAHIR MS, HUSSAIN M, BAE W and KIM HT (2016) Aminated polyethersulfone-silver nanoparticles (AgNPs-APES) composite membranes with controlled silver ion release for antibacterial and water treatment applications. Mater. Sci. Eng. C 62 732-745. http:// dx.doi.org/10.1016/j.msec.2016.02.025

HANAFI Y, LOULERGUE P, ABABOU-GIRARD S, MERIADEC C, RABILLER-BAUDR M , BADDARI K and SZYMCZYK A (2016). Electro kinetic analysis of PES/PVP membranes aged by sodium hypochlorite solutions at different pH. J. Membr. Sci. 501 24-32. http://dx.doi.org/10.1016/j.memsci.2015.11.041

HEGDE C, ISLOOR AM, PADAKI M and FUN H (2013) Synthesis and performance characterization of PS-PPEES nanoporous membranes with nonwoven porous support. Arab. J. Chem. 6 319-326. http://dx.doi.org/10.1016/j.arabjc.2011.05.014

HOU D, DAI G, WANG J, FAN H, ZHANG L and LUAN, Z (2012) Preparation and characterization of PVDF/nonwoven fabric flatsheet composite membranes for desalination through direct contact membrane distillation. Sep. Purif. Technol. 101 1-10. http://dx.doi. org/10.1016/j.seppur.2012.08.031

HU H-Y, DU Y, WU Q-Y., ZHAO X, TANG X and CHEN Z (2016) Differences in dissolved organic matter between reclaimed water source and drinking water source. Sci. Total Environ. 551-552 133-142. http://dx.doi.org/10.1016/j.scitotenv.2015.12.111

HWANG LL, TSENG HH and CHEN JC (2011) Fabrication of polyphenylsulfone /polyetherimide blend membranes for ultrafiltration applications: The effects of blending ratio on membrane properties and humic acid removal performance. J. Membr. Sci. 384 72-81. http://dx.doi.org/10.1016/j.memsci.2011.09.005

JAMSHIDI GOHARI R, LAU WJ, MATSUURA T, HALAKOO E and ISMAIL AF( 2013) Adsorptive removal of $\mathrm{Pb}(\mathrm{II})$ from aqueous solution by novel PES/HMO ultrafiltration mixed matrix membrane. Sep. Purif. Technol. 120 59-68. http://dx.doi.org/10.1016/j. seppur.2013.09.024 
JIAN Q, BOYER TH, YANG X, XIA B and YANG X (2016) Characteristics and DBP formation of dissolved organic matter from leachates of fresh and aged leaf litter. Chemosphere 152 335-344. http://dx.doi.org/10.1016/j.chemosphere.2016.02.107

KIM HC and DEMPSEY BA (2013) Membrane fouling due to alginate, SMP, EfOM, humic acid, and NOM. J. Membr. Sci. 428 190-197. http://dx.doi.org/10.1016/j.memsci.2012.11.004

KIM D, AMY GL and KARANFIL T (2015) Disinfection by-product formation during seawater desalination: a review. Water Res. 81 343-355. http://dx.doi.org/10.1016/j.watres.2015.05.040

LEE J, YE Y, WARD AJ, ZHOU C, CHEN V, MINETT AI, LEE S, LIU Z CHAE S-R and SHI J (2016) High flux and high selectivity carbon nanotube composite membranes for natural organic matter removal. Sep. Purif. Technol. 163 109-119. http://dx.doi.org/10.1016/j. seppur.2016.02.032

LI L, FREY M and BROWNING KJ (2010) Biodegradability study on cotton and polyester fabrics. J. Eng. Fiber Fabric 5 42-53.

LINGE KL, BLYTHE JW, BUSETTI F, BLAIR P, RODRIGUEZ C and HEITZ A (2013) Formation of halogenated disinfection by-products during microfiltration and reverse osmosis treatment: Implications for water recycling. Sep. Purif. Technol. 104 221-228. http://dx.doi. org/10.1016/j.seppur.2012.11.031

MALEK SA, ABU SEMAN MN, JOHNSON D and HILAL N (2012) Formation and characterization of polyethersulfone membranes using different concentrations of polyvinylpyrrolidone. Desalination 288 31-39. http://dx.doi.org/10.1016/j.desal.2011.12.006

MEHRPARVAR A, RAHIMPOUR A and JAHANSHAHI M (2014) Modified ultrafiltration membranes for humic acid removal. J. Taiwan Inst. Chem. E. 45 275-282. http://dx.doi.org/10.1016/j. jtice.2013.06.003

NKAMBULE TI, KRAUSE RWM, HAARHOFF J and MAMBA BB (2012) A three step approach for removing organic matter from South African water sources and treatment plants. Phys. Chem. Earth 50-52 132-139. http://dx.doi.org/10.1016/j.pce.2012.08.009

ORTIZ-MARTÍNEZ K, REDDY P, CABRERA-LAFAURIE WA, ROMÁN FR and HERNÁNDEZ-MALDONADO AJ (2016) Single and multi-component adsorptive removal of bisphenol $A$ and 2,4-dichlorophenol from aqueous solutions with transition metal modified inorganic-organic pillared clay composites: Effect of $\mathrm{pH}$ and presence of humic acid. J. Hazardous Mater. 312 262-271. http:// dx.doi.org/10.1016/j.jhazmat.2016.03.073

PEEVA PD, PALUPI AE and ULBRICHT M (2011) Ultrafiltration of humic acid solutions through unmodified and surface functionalized low-fouling polyethersulfone membranes - effects of feed properties, molecular weight cut-off and membrane chemistry on fouling behaviour and cleanability. Sep. Purif. Technol. 81 124-133. http://dx.doi. org/10.1016/j.seppur.2011.07.005

PEYRAVI M, RAHIMPOUR A, JAHANSHAHI M, JAVADI A and SHOCKRAVI A (2012). Tailoring the surface properties of PES ultrafiltration membranes to reduce the fouling resistance using synthesized hydrophilic copolymer. Micropor. Mesopor. Mater. 160 114-125. http://dx.doi.org/10.1016/j.micromeso.2012.04.036

PHAO N, NXUMALO EN, MAMBA BB and MHLANGA SD (2013) Nitrogen-doped carbon nanotube enhanced polyethersulfone membrane system for water treatment. Phys. Chem. Earth 66 148-156. http://dx.doi.org/10.1016/j.pce.2013.09.009
RIEDL K, GIRARD B and LENCKI RW (1998) Influence of membrane structure on fouling layer morphology during apple juice clarification. J. Membr. Sci. 139 155-166. http://dx.doi.org/10.1016/ S0376-7388(97)00239-1

SAKPAL PP, LANDAGE SM and WASIF AI (2013) Application of nonwovens for water filtration. Int. J. Adv. Res. Manage. Soc. Sci. 2 28-47.

SÄRKKÄ H, VEPSÄLÄINEN M and SILLANPÄÄ M (2015) Natural organic matter (NOM) removal by electrochemical methods - A review. J. Electroanal. Chem. 755 100-108. http://dx.doi. org/10.1016/j.jelechem.2015.07.029

SCHÄFER AL (2001) Natural Organics Removal Using Membranes: Principles, Performance and Cost. Technomic Publishing Co., Inc. Pennsylvania, USA. http://dx.doi.org/10.1201/9781420031638

VANKELECOM IFJ, DE SMET K, GEVERS LEM and JACOBS PA (2003) Nanofiltration: Principles and Applications. Elsevier Publishers, Oxford, UK.

VATSHA, B., NGILA, JC and MOUTLOALI RM (2014) Preparation of antifouling polyvinylpyrrolidone (PVP 40K) modified polyethersulfone (PES) ultrafiltration (UF) membrane for water purification. Phys. Chem. Earth. 67-69 125-131. http://dx.doi.org/10.1016/j. pce.2013.09.021

VIOLLEAU D, ESSIS-TOME H, HABAROUB H, CROUÉ JP and PONTIÉ M (2005) Fouling studies of a polyamide nanofiltration membrane by selected natural organic matter: an analytical approach. Desalination 173 223-238. http://dx.doi.org/10.1016/j. desal.2004.07.048

WANG, CC, YANG, FL, LIU LF, FU ZM and XUE Y (2009) Hydrophilic and antibacterial properties of polyvinyl alcohol/4-vinylpyridine graft polymer modified polypropylene non-woven fabric membranes. J. Membr. Sci. 345 223-232. http://dx.doi.org/10.1016/j. memsci.2009.09.002

WATER USE ASSOCIATION (2011) Seawater desalination power consumption. White Paper. URL: https://www.watereuse.org/.

XUE C, WANG Q, CHU W and TEMPLETON MR (2014) The impact of changes in source water quality on trihalomethane and haloacetonitrile formation in chlorinated drinking water. Chemosphere 117 251-255. http://dx.doi.org/10.1016/j.chemosphere.2014.06.083

YUNOS MZ, HARUN Z, BASRI H and ISMAIL AF (2014) Studies on fouling by natural organic matter (NOM) on polysulfone membranes: effect of polyethylene glycol (PEG). Desalination 333 36-44. http:// dx.doi.org/10.1016/j.desal.2013.11.019

ZHANG Y, ZHAO X, ZHANG X, and PENG S (2015) The change of NOM in a submerged UF membrane with three different pre-treatment processes compared to an individual UF membrane. Desalination 360 118-129. http://dx.doi.org/10.1016/j. desal.2015.01.022

ZINADINI S, ZINATIZADEH AA, RAHIMI M, VATANPOUR V and ZANGENEH H (2014) Preparation of a novel antifouling mixed matrix PES membrane by embedding graphene oxide nanoplates. J. Membr. Sci. 453 292-301. http://dx.doi.org/10.1016/j. memsci.2013.10.070 